\title{
Recherche et développement
}

Oléagineux, Corps Gras, Lipides. Volume 7, Numéro 2, 129, Mars - Avril 2000, Editorial

\author{
Auteur(s) : Jean-Claude ICART
}

Résumé : La présence des sciences sociales au centre de ce dossier, Afrique, plantation et développement, n'est pas seulement significative d'une situation propre au problème du développement des pays du Sud, et de l'Afrique en particulier. Les perspectives, au Nord, d'une agriculture multifonctionnelle, plus sensible aux dimensions territoriales et sociales des ses activités, confrontent la recherche agronomique à des problèmes similaires de médiation, liée aux mêmes impératifs de conciliation entre démarche scientifique et action, imposant le même recours aux analyses sur le milieu socio-économique1.

\section{ARTICLE}

La présence des sciences sociales au centre de ce dossier, Afrique, plantation et développement, n'est pas seulement significative d'une situation propre au problème du développement des pays du Sud, et de l'Afrique en particulier.

Les perspectives, au Nord, d'une agriculture multifonctionnelle, plus sensible aux dimensions territoriales et sociales des ses activités, confrontent la recherche agronomique à des problèmes similaires de médiation, liée aux mêmes impératifs de conciliation entre démarche scientifique et action, imposant le même recours aux analyses sur le milieu socio-économique ${ }^{1}$.

Cette confrontation des expériences qu'ils permettent est aussi une part de l'intérêt de ces travaux « pour " et "sur " le développement des filières oléagineuses africaines réunis ici. Les situations auxquelles ils renvoient étant par ailleurs marquées du sceau d'une tout autre urgence.

On connaît les difficultés de l'Afrique sur le plan macro-économique ${ }^{2}$. Les effets limités sur le processus de développement des pays du Sud, des stratégies récentes encouragées par les institutions financières ont conduit à une situation telle que la prise en compte de leur " économie réelle ", est devenue aujourd'hui, une perspective impérative d'action.

Et si cet engagement se révèle par ailleurs conforme aux nouvelles orientations de la Banque mondiale dont les analyses souhaitent promouvoir désormais un " développement social durable ", conçu comme un processus de croissance économique "intégré ", et prenant "en compte les populations, leur culture ainsi que leurs organisations et institutions ", le problème de terrain, ainsi posé à la recherche agronomique n'en est pas moins crucial.

Comment agir, quel transfert de connaissance opérer, quelle médiation mettre en place, quelle productivité rechercher hors des solutions normalisées de type agro-industriel en vigueur depuis des décennies ? Comment intervenir dans un contexte caractérisé par une floraison de plantations villageoises associées à une extrême diversité de systèmes de culture et que personne n'appréhende et $a$ fortiori ne maîtrise encore vraiment ? 
Ce sont ces analyses préalables sur les conditions dans lesquelles l'aide peut être apportée et les débuts du dialogue que cette action implique entre sociologues et agronomes qui sont ici présentées, une réflexion qui place la recherche dans une situation pionnière, conduit le chercheur, tel un médecin, à se faire à la fois homme de science, de pratique et de relation ${ }^{3}$.

Si le succès de ces démarches dépend aussi de conditions générales, comme la " bonne gouvernance » et l'amélioration de l'appui de la communauté internationale (qui n'en prend pas le chemin : voir l'article de V. Ribier et T. Voituriez) elles n'en concernent pas moins à une part essentielle de la réalité d'un continent qui dépassera le milliard d'habitants d'ici vingt ans et dont la moitié de la population sera encore rurale.

Notes

${ }^{1}$ Voir « Recherches pour et sur le développement territorial », Symposium de Montpellier, 1112/01/2000. INRA, DADP.

${ }^{2}$ Voir, L'Afrique doit opérer des changements majeurs pour entrer dans le xxi ${ }^{e}$ siècle, http://media.worldbank.org/secure/africa/363fr.pdf

${ }^{3}$ Un colloque, L'avenir des cultures pérennes, Yamoussoukro, Octobre 2001, fera le point sur ces questions. Contact: D. Nicolas, Cirad. Fax: 33467615659. 